\title{
Cultural tourism and quality of life: Results of a longitudinal study
}

\author{
Amanda K. Cecil ${ }^{1}$, Yao-Yi Fu ${ }^{1}$, Suosheng Wang ${ }^{1}$, Sotiris Avgoustis ${ }^{1 \star}$
}

Received: 14/09/2009 Accepted: 31/01/2010

\footnotetext{
${ }^{1}$ Department of Tourism, Convention and Event Management, Indiana University, Indianapolis.

* Corresponding author e-mail: savgoust@iupui.edu
}

\begin{abstract}
Cultural tourism development is considered a viable channel to attract tourists to a destination and to enhance residents' overall quality of life (QOL). Since the early 2000's, Indianapolis, Indiana has dedicated considerable public and private investment into developing and promoting cultural attractions, festivals, educational events, and other offerings. This research reports the findings of a five-year study, from 2004-2008, to monitor patterns and changes in residents' quality of life (QOL) measurement and perceptions of cultural tourism. The results indicate that there are not significant increases in QOL ratings of Indianapolis residents, as it relates to cultural tourism development. However, the series of studies yield interesting conclusions that have practical implications for municipality and tourism leaders who continually evaluate the city's cultural tourism initiatives.
\end{abstract}

(c) 2010 International University College. All rights reserved

Keywords: cultural tourism, quality of life, longitudinal study

Citation: Cecil A.K., Y.Y. Fu, S. Wang, S. Avgoustis (2010) Cultural tourism and quality of life: Results of a longitudinal study. European Journal of Tourism Research 3(1), pp. 54-66

\section{Introduction}

In 2002, Indianapolis formed the Indianapolis Cultural Development Commission and embarked on a cultural tourism initiative. One of the first projects of the Commission was the creation of the Cultural Districts Program to facilitate the cultural development of six distinct neighborhoods that offered a unique mix of arts, cultural and hospitality activities. The development of these six neighborhoods was designed to share the authentic and diverse character of Indianapolis and its people with residents and visitors alike. The initiative also helped to increase public art in the downtown area. The main goal of this program was to improve the quality of life (QOL) of its residents through the promotion and creation of cultural offerings in the greater Indianapolis area.

Increasingly, many cities evaluate the impact of cultural tourism solely as a driver of future economic growth. However, the full picture of the impact of cultural tourism upon urban environments is not well understood. The overall purpose of this longitudinal study was to evaluate non-economic measures for the city of Indianapolis before full implementation of the initiative and to create a baseline index to determine the relationship between the level of awareness, importance and impact of the cultural tourism initiative and residents' perceived QOL rating. The project started in 
2003 with the research team hosting a town hall meeting to discuss the new Indianapolis cultural tourism initiative and a series of papers have been published that include findings on city services that predict successful tourism development (Avgoustis, Cecil, Fu, \& Wang, $2005 \& 2007)$ and comparison studies of impact of cultural tourism upon residents' QOL (Wang, Cecil, Fu, \& Avgoustis, 2006 \& 2008).

The QOL of an urban population is an important concern in achieving economic prosperity through tourism development. There are many components involved in measuring an urban residents' QOL; however, a focus tends to be on residents' standard of living, the amount of money earned, and their access to goods and services. These statistics are easily recorded, measured, and evaluated. Other statistics that attempt to measure alternative dimensions of urban living, such as mental and physical happiness, culture, and environmental health and safety are far more difficult to measure. This has created an inevitable imbalance, as programs and policies are created to fit the easily available economic numbers while ignoring the other measures.

The nature of this longitudinal project has focused on three primary objectives:

1. To measure QOL dimensions using Raphael, Steinmetz, and Renwick's (1998) model - "being", "becoming" and "belonging"

2. To examine awareness and value of cultural tourism in Indianapolis

3. To evaluate the relationship of awareness and value of cultural tourism and the resident's overall QOL ratings.

\section{Literature review}

\section{Cultural Tourism}

High quality and diverse cultural offerings raise a city's profile and attract inward investment resulting in positive economic impact (Law, 2002). Cultural attractions such as museums, art galleries, theaters, festivals, and convention centers draw leisure and business tourists to a city. People who live in smaller places have to travel to a city to experience culture amenities, facilities and events that are not available in their local places.
Cultural tourism is growing with the changing travel trends and tourist demographics. Tourists are currently taking shorter vacations, mainly in urban destinations, and a more sophisticated and educated tourist is emerging. According to Cabrini (2003) Europe continues to attract increasing numbers of tourists to its cultural locations. The European Commission reported $20 \%$ of European tourists are responding to cultural motivations, while $60 \%$ of European tourists are interested in cultural discovery during their stay. As tourism popularity and international travel continues to increase, cultural tourism interest will additionally see a substantial increase (Cabrini, 2003). Additionally, interest in cultural tourism peaks for individuals between the ages 45 and 65 . As the population life expectancy continues to raise, so will the interest in cultural tourism (Cameron, 1993).

Cultural tourism defined by the Indianapolis Cultural Development Commission is "experiencing the diverse mosaic of places, traditions, arts, celebrations and experiences that the Indianapolis area offers to residents and visitors. It is an important component of an overall tourism plan that emphasizes the total Indianapolis experience" (1). Furthermore, the commission states, "In addition to all the growth and expansion Indy is experiencing and will continue to experience, there is even more to celebrate. A powerful sports schedule, exciting national conventions, landmark anniversaries, and new summer celebrations will together tell the Indianapolis story. It's a chance for the city to be recognized for the cultural destination that it is" (Indianapolis Cultural Development Commission, 2004, 1).

\section{Quality of Life (QOL) Measurements}

Quality of life (QOL) can have multiple meanings to different individuals and be used in a variety of contexts in research studies. Some would argue that in order for a community to enjoy a good QOL, residents should feel safe from crime, live in affordable and high quality housing, and have access to quality education and employment opportunities. Indeed, these are basic 
expectations for a livable community. These indicators go beyond economic status, age, race, household composition, or any other demographic indicator.

In their study, Diener and Shu (1997) compared different approaches of defining and measuring quality of life: subjective well-being measures, economic indices, and social indicators such as crime level, health, and leisure opportunities. They pointed out that economic progress alone may not guarantee happiness if people do not have satisfactory leisure time or live in a crime-ridden environment. This study suggested that social indictors are relatively easy to define and quantify and capture important aspects of society. Although social indictors are often thought to be objective, they are sometimes contaminated by measurement problems. The researcher mentioned that subjective wellbeing measures include three components: life satisfaction, pleasant affect, and unpleasant affect with life domains such as work and leisure. A major strength of subjective measures is that they capture experiences that are important to individuals. While most social indicators are indirect assessment of how people feel about their life, subjective wellbeing measures provide additional evaluation. If researchers unite the two approaches of measuring quality of life, it allows researchers to make more definitive conclusions. Diener and Shu (1997) suggested that since each approach has its strengths and weaknesses, there is a need to unify social indicators, subjective well-being measures, and economic indices to better understand quality of life.

Increasingly cities and regions in major metropolitan areas throughout the United States are developing locally-based measures to assess QOL. For example, a volunteer civic project called "Sustainable Seattle" introduced the concept of sustainability indicators for a metropolitan region with a pioneering report in 1993. They were inspired by Jacksonville, Florida's "QOL" measures and the State of Oregon's growth-oriented "Benchmarks." The researchers of "Sustainable Seattle" took a unique approach to measure progress towards true sustainability (Sustainable Seattle, 2006).
Studies, like the above projects, have used over 200 indicators of QOL. They have assessed QOL at the neighbourhood, city, county and/or the regional level. Some have collected distinctive measures of QOL reflective of local environmental, social, and economic condition, while most communities have simply relied on data from the U.S. Census. The concept of QOL as a multi-faceted concept seeks to include a wide variety of critical variables within a unified framework.

Relationship between Cultural Tourism and QOL

Several studies have addressed issues related to the ability of travel and tourism to both enhance and diminish the QOL of local residents in the host community (Cohen, 1978; Linton, 1987; Williams \& Shaw, 1988; Jurowski, Uysal, \& Williams, 1997; Perdue, Long, \& Allen, 1990). Anderson and Nurick (2002) consider that the conventional economic appraisal of cultural projects only focuses on the 'measurement of the measurable,' such as the number of visitors attracted to the cultural destination, the number of jobs created due to tourism niche, and economic benefits of the project and tourism financial impact. On the other hand, the authors argue that an economic appraisal does not address other aspects of QOL regarding the places and regions which cultural projects are located. The challenge lies in how to measure the changed image and aspirations of a location and the QOL of its residents due to cultural impact. Their findings indicate increasing evidence that $\mathrm{QOL}$ is becoming an important factor in relocationrelated decisions for both skilled workers and business investors. The study further illustrates that cultural projects can greatly strengthen a city's brand or image and cause it to be perceived more favorably.

Kim (2002) investigated how tourism development influences the QOL of residents in different stages of development. Overall satisfaction with life was used as the measurement for QOL. The results show that tourism development did affect people's overall life satisfaction. During the initial stage of tourism development, residents may feel stress 
caused by change and demand for more public services and infrastructure. People's life satisfaction is higher during the maturity stage of tourism development. When tourism development enters its declining stage, QOL may also start to decline.

Avgoustis, Cecil, Fu, and Wang (2005) examined the impact of cultural tourism on QOL in Indianapolis. The researchers adopted Raphael, et. al (1998) measurements of three dimensions of QOL that include "being" (physical characteristics), "belonging" (environmental characteristics), and "becoming" (emotional, mental and spiritual characteristics). Their results indicate that people's understanding of the importance of cultural tourism development did play a positive role in affecting people's perception of their QOL in the dimensions of "being", "belonging" and "becoming."

The same group of researchers continued their study of the relationship between cultural tourism and QOL in 2005, and then compared the 2004 and 2005 survey results (Wang, Fu, Cecil, \& Avgoustis, 2006). In terms of awareness, importance and impact cultural tourism, they found that residents' perceptions of cultural tourism were mostly the same. Regarding the QOL issue, residents' ratings on "being" and "belonging" were significantly improved from 2004 to 2005 for all four demographic variables: gender, age, length of residency, and income. Notably, the dimension "becoming" reported a decline in 2005 regardless of one's gender, age, length of residency, or income.

In a more recent study, Yamada, Heo, King, and $\mathrm{Fu}$ (2009) considered cultural tourism as one of the life domains and examined how cultural tourism along with four other life domains: health perception, wealth, safety, and community pride influence life satisfaction of urban residents. Their results show that the five life domains were positively related to life satisfaction. They concluded that life satisfaction is a benefit derived from cultural tourism development.

\section{Methodology}

From 2004-2008, a series of surveys were conducted in the month of September to measure Indianapolis residents' perception of their QOL, to evaluate observations of cultural tourism development, and to explore the relationships between residents' QOL and cultural tourism development.

\section{Instrument Design}

For the purpose of this study, the researchers relied on an adaptation of a model developed by Raphael et al. (1998) to design, pilot-test, and administer the questionnaire to Indianapolis residents. This community approach to quality of life was centered on people's perception of what would or would not make their lives satisfactory. The study questionnaires assumed that certain community dimensions affect people's quality of life. Quality of life were assessed based on three major indicators: "being", which reflects "who the individual is" and has physical components; "belonging", which involves people's relationship with their environments; and "becoming", which involves individual activities to achieve individual emotional, mental and spiritual goals, hopes and aspirations.

As a result, a set of $\mathrm{QOL}$ attributes were identified and a number of cultural tourism elements were developed. Additionally, a number of QOL attributes have been included in the survey each year from 2004-2008. Residents' QOL was measured using five-point scales in the following five categories including (a) QOL1: overall health (from 1-extremely good to 5-extremely poor), (b) QOL2: frequency of physical activity (from 1-everyday to 5-never), (c) QOL3: happiness (from 1-all of the time to 5-never), (d) QOL4: stress level (from 1-no stress at all to 5-stress extremely negative), and (e) QOL5: sense of community (from 1-strongly agree to 5-strongly disagree) . The item of "overall satisfaction with the QOL in Indianapolis" with a five-point Likert scale was added to the survey in 2007 and 2008.

The cultural tourism items were measured on a five-point Likert scale ranging from strongly 
agree (1)" to "strongly disagree (5)". A set of cultural tourism items were developed reflecting residents' perceptions of various aspects including residents' awareness of the cultural tourism campaign, perceived benefits to the city, residents' satisfaction and enjoyment with tourism, dependence on public and private support and potential success of the cultural tourism marketing campaign. Specifically, consistent items used for all five years included are (a) Culture1: diverse individuals in city (b) Culture2: enjoyment of cultural attractions, (c) Culture3: awareness of accomplishments, (d) Culture4: promotion of unique cultural tourism areas or projects, and (e) Culture5: potential future success.

Questions regarding respondents' demographic characteristics, such as age, gender, ethnicity, household income, and length of residency were included to paint a picture of the demographic profile of respondents over the five-year span.

Instrument Administration

Each year from 2004 to 2008, the research team used the convenience sampling technique in a high-traffic downtown area and Indianapolis residents were selected on the basis of their availability. All research participants were 18 years of age or older, residents of Indianapolis, and volunteered to participate. Upper-level, undergraduate students were involved in the data collection process and were supervised by faculty researchers. The research team collected 760 surveys in 2004, 760 in 2005, 995 in 2006, 355 in 2007, and 391 in 2008.

\section{Data Analysis}

All the data sets were entered into SPSS for data analyses. Frequency analysis was used to showcase the demographic distributions of respondents from 2004 to 2008. The mean ratings of all the perceptional items, both QOL attributes and cultural tourism items, were computed and tabled. Independent samples ttest was employed to compare both the QOL attributes and cultural tourism items between different demographic groups. Correlation analysis was conducted to test the relationship between respondents' overall QOL satisfaction with the cultural tourism items.

\section{Results \\ Demographic Profile}

Table 1 shows the distributions of different demographic groups in terms of gender, ethnicity, household income and length of residency in Indianapolis. As shown in Table 1, the ratio of males to females was equally distributed (53.2\% male and $46.8 \%$ female) throughout the five-year time period.

The most frequently reported age group was the younger group (18-30 years old), ranging from $31.6 \%$ to $43.1 \%$, while the age groups of 31-43 and 44-56 years were the two other major groups, ranging from $25.2 \%$ to $31.3 \%$. A small proportion, less than a total of $10 \%$, came from the older age group of over 56 years old.

In terms of ethnicity, "White, not of Hispanic Origin" has been the majority group as compared to other ethnic groups ranging from $61.2 \%$ to $76.3 \%$ for the five years. The second largest group is "Black, not of Hispanic Origin," ranging from $11.6 \%$ to $20.4 \%$. The "household income" has been dominated by medium and low income groups, specifically, " $\$ 30,001-$ $\$ 60,000 "$ and $\$ 0-\$ 30,000$." Except for 2008, these two groups added up for over $50 \%$ of the total number of respondents. Among all the respondents, over half of them have lived in the city of Indianapolis at least 10 years.

Tables 2 and 3 display the changing style of respondents' perceptions of the QOL attributes and cultural tourism items. Cell values indicate the percentages of respondents from 20042008 who perceived all the QOL categories positively. As shown from the below table, there are no distinct increasing or decreasing pattern shown by these QOL attributes between 2004 and 2008. One exception is the stress variable which indicates that there is a steady increase of people who experience "no stress" or "only some non-negative stress in the last 12 months." The response percentage for this item increased from $59.4 \%$ in 2004 to $66.7 \%$ in the year of 2008 . 
Table 1: Summary Report of Respondents' Demographic Profile (2004-2008) (in percent)

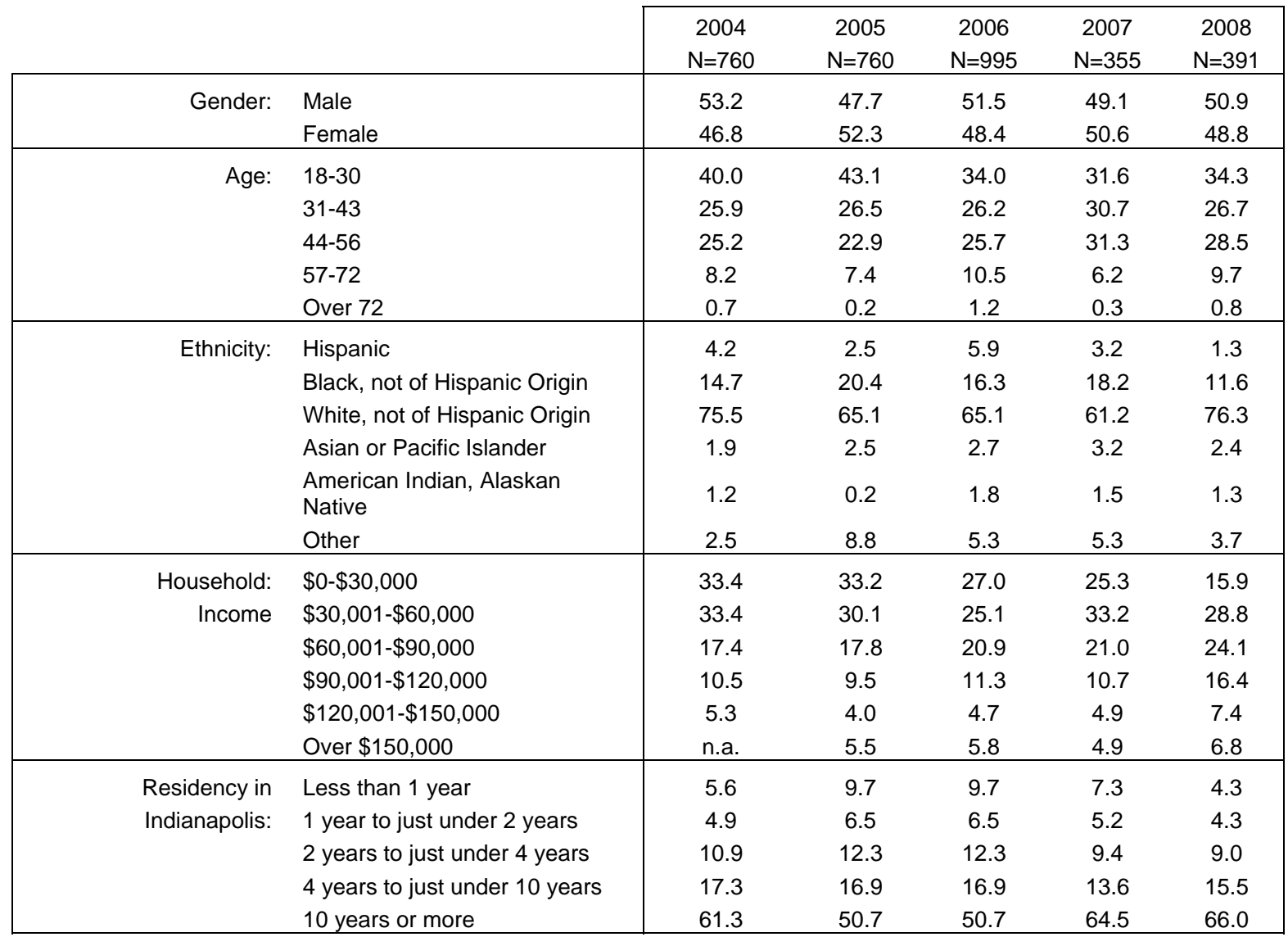

The situation is very similar to the changing style of respondents' perception of cultural tourism items. One of the five items, awareness of the city's cultural tourism campaigns, showed a steady improvement. Resident's awareness of Indianapolis' cultural district program and the development of the cultural trail reported a mean rating of 3.04 in 2004 and 2.66 of 2008 . No other patterns were identified amongst the additional four cultural tourism items.

One of the major objectives of this longitudinal study was to test the existence and reliability of perceptual differences between different demographic groups such as gender, age, ethnicity, etc. In each demographic category with more than two subsets, the two groups with distinct differences were paired for t-test. Meanwhile, groups with a limited number of respondents were excluded from the t-test. As a result, demographic groups for comparisons include males vs. females, age groups "18-30" vs. "57-72", black vs. white, not of Hispanic Origin, income of $\$ 0-\$ 30000$ vs. over $\$ 90000$, and length of residency for 2-4 years vs. 10 or more years. 
Table 2: Trend Summary of Respondents' QOL Attributes (2004-2008)

\begin{tabular}{|l|l|l|l|l|l|}
\hline Items & 2004 & 2005 & 2006 & 2007 & 2008 \\
\hline $\begin{array}{l}\text { Compare to other people of your age, your overall } \\
\text { health is good or extremely good }\end{array}$ & 80.4 & 76.05 & 72.5 & 76.9 & 84.5 \\
\hline $\begin{array}{l}\text { Each week you take part in physical activities at } \\
\text { least 2-4 times }\end{array}$ & 62.6 & 60.0 & 52.3 & 64.1 & 64.2 \\
\hline $\begin{array}{l}\text { You have been happy most of the time or all of the } \\
\text { time over the last 12 months }\end{array}$ & 57.4 & 55.7 & 54.1 & 55.2 & 54.5 \\
\hline $\begin{array}{l}\text { You experienced no stress in the last 12 months or } \\
\text { some stress that only had a slight negative or even } \\
\text { no negative effect }\end{array}$ & 59.4 & 63.0 & 63.8 & 65.6 & 66.7 \\
\hline $\begin{array}{l}\text { You agree or strongly agree that you feel a sense } \\
\text { of community with others in Indy }\end{array}$ & 46.7 & 44.0 & 44.9 & 43.2 & 42.7 \\
\hline
\end{tabular}

Table 3: Trend Summary of Respondents' Perceptions of Cultural Tourism in Indianapolis (2004-2008)

\begin{tabular}{|c|c|c|c|c|c|}
\hline \multirow{3}{*}{ Items } & \multicolumn{5}{|c|}{ Mean } \\
\hline & 2004 & 2005 & 2006 & 2007 & 2008 \\
\hline & $(\mathrm{N}=760)$ & $(N=760)$ & $(\mathrm{N}=995)$ & $(N=355)$ & $(N=391)$ \\
\hline $\begin{array}{l}\text { Impact of diversity cultures (1-a much better place, 5-much } \\
\text { worse) })^{1}\end{array}$ & 2.16 & 2.23 & 2.20 & 2.41 & 2.22 \\
\hline $\begin{array}{l}\text { Enjoy cultural attractions (1-strongly agree, 5-strongly } \\
\text { disagree) })^{2}\end{array}$ & 2.36 & 2.51 & 2.25 & 2.34 & 2.46 \\
\hline $\begin{array}{l}\text { Aware of accomplishments (1-strongly agree, 5-strongly } \\
\text { disagree) }\end{array}$ & 2.87 & 2.88 & 2.79 & 2.74 & 2.83 \\
\hline $\begin{array}{l}\text { Aware of cultural programs (1-strongly agree, 5-strongly } \\
\text { disagree) }{ }^{4}\end{array}$ & 3.04 & 2.97 & 2.80 & 2.73 & 2.66 \\
\hline Potential to succeed (1-strongly agree, 5-strongly disagree) ${ }^{5}$ & 2.32 & 2.38 & 2.22 & 2.51 & 2.72 \\
\hline
\end{tabular}

${ }^{1}$ Impact on Indianapolis from diversity of lifestyles and cultures

2 I enjoy the cultural attractions the city has to offer

3 I am aware of the city's recent accomplishments in cultural tourism

${ }^{4}$ I am aware of the city's cultural district program or plans for developing cultural trail

${ }^{5}$ Indianapolis has the potential to succeed as a cultural tourism destination 
Table 4: Perceived Difference of QOL Attributes between Different Demographic Groups (from 2004-2008)

\begin{tabular}{|c|c|c|c|c|c|c|c|c|c|c|}
\hline & \multicolumn{2}{|l|}{2004} & \multicolumn{2}{|l|}{2005} & \multicolumn{2}{|l|}{2006} & \multicolumn{2}{|l|}{2007} & \multicolumn{2}{|l|}{2008} \\
\hline \multicolumn{11}{|c|}{ Gender: male vs. female } \\
\hline & $\mathrm{t}$ & alpha & $\mathrm{T}$ & alpha & $\mathrm{t}$ & alpha & $\mathrm{T}$ & alpha & $\mathrm{t}$ & alpha \\
\hline QOL1 & -1.12 & 0.26 & -2.16 & 0.03 & -0.29 & 0.78 & 0.69 & 0.49 & -0.40 & 0.69 \\
\hline QOL2 & -3.06 & 0.01 & -1.26 & 0.21 & -1.33 & 0.19 & 0.14 & 0.89 & -2.08 & 0.04 \\
\hline QOL3 & 2.72 & 0.01 & -1.42 & 0.16 & 1.95 & 0.05 & 0.02 & 0.99 & 0.40 & 0.69 \\
\hline QOL4 & 1.26 & 0.21 & -2.09 & 0.04 & 0.30 & 0.77 & 0.55 & 0.58 & -0.14 & 0.89 \\
\hline QOL5 & 0.79 & 0.43 & -1.93 & 0.05 & -1.51 & 0.13 & 0.04 & 0.97 & -1.51 & 0.13 \\
\hline \multicolumn{11}{|c|}{ Age: age $18-30$ vs. $57-72$} \\
\hline & $\mathrm{T}$ & alpha & $\mathrm{T}$ & alpha & $\mathrm{t}$ & alpha & $T$ & alpha & $\mathrm{t}$ & alpha \\
\hline QOL1 & -1.58 & 0.12 & 0.27 & 0.78 & -0.40 & 0.69 & 0.20 & 0.84 & 1.60 & 0.11 \\
\hline QOL2 & -2.53 & 0.01 & 0.39 & 0.70 & -1.99 & 0.04 & 1.40 & 0.17 & -2.00 & 0.05 \\
\hline QOL3 & 1.37 & 0.17 & 0.04 & 0.97 & -1.68 & 0.09 & .52 & 0.60 & 0.08 & 0.94 \\
\hline QOL4 & -0.88 & 0.38 & -0.01 & 0.99 & -0.98 & 0.33 & 0.07 & 0.95 & 1.79 & 0.08 \\
\hline QOL5 & 2.46 & 0.01 & 2.03 & 0.04 & 0.83 & 0.41 & 1.85 & 0.07 & 0.40 & 0.72 \\
\hline \multicolumn{11}{|c|}{ Ethnicity: black vs. white (not of Hispanic origin) } \\
\hline & $\mathrm{t}$ & alpha & $\mathrm{T}$ & alpha & $\mathrm{t}$ & alpha & $\mathrm{T}$ & alpha & $\mathrm{t}$ & alpha \\
\hline QOL1 & -0.41 & 0.68 & -0.27 & 0.79 & 2.50 & 0.01 & 0.51 & 0.61 & 0.53 & 0.59 \\
\hline QOL2 & 0.29 & 0.77 & 2.47 & 0.01 & 3.20 & 0.01 & 0.43 & 0.67 & 0.56 & 0.58 \\
\hline QOL3 & 0.99 & 0.33 & 0.77 & 0.44 & 1.01 & 0.31 & 1.55 & 0.12 & 0.92 & 0.36 \\
\hline QOL4 & 0.52 & 0.60 & -3.26 & 0.01 & -3.71 & 0.01 & 1.57 & 0.12 & -2.01 & 0.04 \\
\hline QOL5 & -1.27 & 0.20 & -0.85 & 0.40 & 1.18 & 0.24 & 0.15 & 0.88 & 1.35 & 0.18 \\
\hline \multicolumn{11}{|c|}{ Income: $\$ 0-\$ 30,000$ vs. over 90,000} \\
\hline & $\mathrm{t}$ & alpha & $\mathrm{T}$ & alpha & $\mathrm{t}$ & alpha & $\mathrm{T}$ & alpha & $T$ & alpha \\
\hline QOL1 & 1.76 & 0.08 & 1.99 & 0.04 & 2.32 & 0.02 & 0.99 & 0.33 & 0.89 & 0.37 \\
\hline QOL2 & 0.83 & 0.41 & 0.46 & 0.65 & 3.06 & 0.01 & 0.54 & 0.59 & 1.56 & 0.12 \\
\hline QOL3 & 2.93 & 0.01 & 1.39 & 0.17 & 2.03 & 0.04 & 0.52 & 0.60 & 0.82 & 0.41 \\
\hline QOL4 & -0.43 & 0.67 & -0.01 & 0.99 & -.19 & 0.85 & 1.76 & 0.09 & 0.66 & 0.51 \\
\hline QOL5 & 3.55 & 0.01 & 0.64 & 0.53 & 2.72 & 0.01 & 0.74 & 0.46 & 1.04 & 0.30 \\
\hline \multicolumn{11}{|c|}{ Length of stay: 2 years to just under 4 years vs. 10 years or more } \\
\hline & $\mathrm{t}$ & alpha & $\mathrm{T}$ & alpha & $\mathrm{t}$ & alpha & $T$ & alpha & $T$ & alpha \\
\hline QOL1 & -0.89 & 0.37 & 2.42 & 0.02 & 0.22 & 0.83 & 0.03 & 0.98 & 1.07 & 0.29 \\
\hline QOL2 & -0.17 & 0.87 & -0.33 & 0.74 & 0.52 & 0.60 & -0.02 & 0.99 & 0.78 & 0.43 \\
\hline QOL3 & 0.84 & 0.40 & -1.24 & 0.21 & 0.45 & 0.65 & -0.21 & 0.83 & 1.36 & 0.18 \\
\hline QOL4 & 0.69 & 0.49 & 1.58 & 0.11 & -2.61 & 0.01 & -0.75 & 0.45 & 0.20 & 0.84 \\
\hline QOL5 & 0.76 & 0.45 & 2.27 & 0.02 & -0.93 & 0.35 & -1.50 & 0.14 & -0.19 & 0.85 \\
\hline
\end{tabular}

QOL1: compared to other people of your age, would you say your overall health is ...? (1-extremely good, 5-extremely poor);

QOL2: how often do you take in physical activity, that increases your heart rate or breathing for 30 minutes or more? (1everyday or nearly everyday, 5-once or less a month);

QOL3: how much time would you say you have been happy over the last 12 months? (1-all of the time, 5-hardly ever); QOL4: Which of the following best describes the stress you have experienced on occasions in the last 12 months? (1experienced no stress at all, 5-experienced stress having extremely negative effect)

QOL5: I feel a sense of community with others in Indianapolis (1-strongly agree, 5 strongly disagree) 
Table 4 (see table above) shows the results of all the t-tests in defining the perceived difference of QOL attributes between the above-mentioned demographic groups. While the results of the longitudinal t-tests showed significant results in some years and then nonsignificance in other years, the following test results are consistent and considered to be more reliable because they were collected during a span of five years. These tests are: (a) QOL1, QOL3 and QOL4, between different age groups (18-30 vs. 57-72), (b) QOL3 and QOL5, between black and white (not of Hispanic origin, (c) QOL4, between people of different household income $(\$ 0-\$ 30000$ vs. over \$90000), and (d) QOL2 and QOL3, between residents 2-4 years and residents over 10 years. None of the above tests were significant.

Apart from these tests, a majority of the longitudinal tests showed non-significance of the results except for a selected few tests that were significant. Hence, it can be concluded that there are no evidence to differentiate individuals' perceptions of their QOL based upon one's gender, age, ethnicity, income, and length of residency.

Table 5 shows the results of all the t-tests on the cultural tourism items between different demographic group: gender, age, ethnicity, income and length of residency. As shown on Table 5, the results are very similar to that of Table 4, in that most of the t-test results are not significant. Even for those items being tested to be significant based on one or two samples of the five-year surveys, the other samples failed to generate the same results for the same items. In general, there is a lack of reliable evidence to conclude that people's perceptions on cultural tourism development are different.

Apart from the tests featuring a random distribution of being significant or not significant, the tests on the following cultural tourism items showed consistency of nonsignificance of the results: (a) Culture4, between males and females, (b) Culture5, between the age group of 18-30 and 57-72; (c) Culture5, between black and white (not of Hispanic origin); (d) Culture1, Culture2 and Culture5, between a household income of $\$ 0$ -
$\$ 30000$ and an income over $\$ 90000$, and (e) Culture1 and Culture2, between residents for 24 years and for over 10 years. Based on all the results of the five samples, a pattern did not emerge in relation to the difference of respondents' perceptions in the area of cultural tourism development.

Table 6 summarizes the results of correlation analyses between the variable of respondents' overall satisfaction with their $\mathrm{QOL}$ and the cultural tourism related items based on the two samples collected in 2007 and 2008. Based on the comparison of the correlation coefficient and the actual p-value of each test, the results of 2007 and 2008 indicate that respondents' overall QOL satisfaction is positively but not strongly correlated with the items of Culture2 "I enjoy the cultural attractions the city has to offer" and Culture5 - "Indy has the potential to succeed as a cultural tourism destination." The different between the results of the two years of tests is Culture 1 - "An increasing number of people of different cultures makes Indy a much better place to live" and Culture4 - "I am aware of the city's cultural district program or the city's plans for developing the cultural trail", where Culture 1 is only found to be positively and moderately correlated with QOL satisfaction in the 2007 test and Culture 4 to be only significant in 2008. Among these items, Culture3 - "I am aware of the city's recent accomplishments in cultural tourism" is not found to be significantly correlated with QOL satisfaction in either test of 2007 or 2008.

\section{Discussion and conclusions}

A primary objective of the cultural tourism development initiative was to improve the QOL for Indianapolis residents by capitalizing on the city's increasing cultural amenities and attributes. This longitudinal study, conducted from 2004 to 2008, measured if the cultural tourism initiative helped to improve QOL. The study found there was some positive impact of cultural tourism on QOL; however, the impact was random over the years and there was no consistent pattern, either positive or negative, since the beginning of the initiative. This finding differs from Kim's (2002) study that he found tourism development initially had negative impact on QOL but in the later stage of tourism development, the impact become positive. 
Cecil A.K., Y.Y. Fu, S. Wang, S. Avgoustis (2010) European Journal of Tourism Research 3(1), pp. 54-66

Table 5: Perceived Difference of Cultural Tourism items between Different Demographic Groups (from 2004-2008)

\begin{tabular}{|c|c|c|c|c|c|c|c|c|c|c|}
\hline & \multicolumn{2}{|l|}{2004} & \multicolumn{2}{|l|}{2005} & \multicolumn{2}{|l|}{2006} & \multicolumn{2}{|l|}{2007} & \multicolumn{2}{|l|}{2008} \\
\hline \multicolumn{11}{|c|}{ Gender: male vs. female } \\
\hline & $\mathrm{t}$ & alpha & $\mathrm{T}$ & alpha & $\mathrm{t}$ & alpha & $\mathrm{T}$ & alpha & $T$ & alpha \\
\hline Culture1 & 0.69 & 0.49 & 0.63 & 0.53 & -0.37 & 0.71 & -2.37 & 0.02 & 0.12 & 0.90 \\
\hline Culture2 & 2.84 & 0.01 & 1.24 & 0.21 & 1.30 & 0.19 & 0.12 & 0.90 & 1.50 & 0.14 \\
\hline Culture3 & -0.25 & 0.80 & -0.02 & 0.98 & 0.59 & 0.55 & 1.44 & 0.15 & -1.97 & 0.04 \\
\hline Culture4 & -0.60 & 0.95 & -0.67 & 0.50 & 0.45 & 0.65 & 0.11 & 0.91 & 1.40 & 0.16 \\
\hline Culture5 & 1.03 & 0.31 & 0.87 & 0.38 & 1.73 & 0.08 & 0.35 & 0.73 & 2.74 & 0.01 \\
\hline \multicolumn{11}{|c|}{ Age: age $18-30$ vs. $57-72$} \\
\hline & $\mathrm{t}$ & alpha & $\mathrm{T}$ & alpha & $\mathrm{t}$ & alpha & $\mathrm{T}$ & alpha & $\mathrm{T}$ & alpha \\
\hline Culture1 & -2.35 & 0.02 & 0.87 & 0.39 & -1.78 & 0.08 & -2.19 & 0.03 & -0.89 & 0.38 \\
\hline Culture2 & 0.33 & 0.74 & 1.40 & 0.16 & 2.75 & 0.01 & 1.66 & 0.10 & 3.33 & 0.01 \\
\hline Culture3 & 1.80 & 0.07 & 0.84 & 0.40 & 0.90 & 0.37 & 2.78 & 0.01 & 2.64 & 0.01 \\
\hline Culture4 & 2.22 & 0.03 & 0.46 & 0.65 & 1.73 & 0.09 & 1.56 & 0.12 & 2.44 & 0.02 \\
\hline Culture5 & -0.26 & 0.79 & 0.17 & 0.86 & 0.95 & 0.35 & 0.72 & 0.47 & 1.56 & 0.12 \\
\hline \multicolumn{11}{|c|}{ Ethnicity: black vs. white (not of Hispanic origin) } \\
\hline & $\mathrm{t}$ & alpha & $\mathrm{T}$ & alpha & $\mathrm{t}$ & alpha & $\mathrm{T}$ & alpha & $\mathrm{T}$ & alpha \\
\hline Culture1 & -.61 & 0.54 & -0.14 & 0.89 & -1.11 & 0.27 & 0.81 & 0.42 & -2.99 & 0.01 \\
\hline Culture2 & -1.25 & 0.21 & 0.61 & 0.55 & -0.19 & 0.85 & 2.42 & 0.02 & -1.09 & 0.28 \\
\hline Culture3 & -3.66 & 0.01 & -0.61 & 0.54 & -0.32 & 0.75 & 1.45 & 0.15 & -0.07 & 0.95 \\
\hline Culture4 & -3.48 & 0.01 & 0.13 & 0.89 & -0.07 & 0.94 & 2.23 & 0.03 & -0.30 & 0.77 \\
\hline Culture5 & -1.76 & 0.08 & -0.10 & 0.92 & -0.21 & 0.84 & 0.82 & 0.41 & 0.26 & 0.79 \\
\hline \multicolumn{11}{|c|}{ Income: $\$ 0-\$ 30,000$ vs. over 90,000} \\
\hline & $\mathrm{t}$ & alpha & $\mathrm{T}$ & alpha & $\mathrm{t}$ & alpha & $\mathrm{T}$ & alpha & $\mathrm{T}$ & alpha \\
\hline Culture1 & 0.46 & 0.65 & 0.49 & 0.62 & -0.49 & 0.62 & 0.11 & 0.91 & -1.00 & 0.32 \\
\hline Culture2 & 1.19 & 0.24 & -0.67 & 0.50 & 1.28 & 0.20 & -0.04 & 0.97 & .64 & 0.52 \\
\hline Culture3 & -0.10 & 0.92 & -0.12 & 0.91 & 0.65 & 0.51 & 0.12 & 0.91 & 2.30 & 0.02 \\
\hline Culture4 & -1.09 & 0.28 & -1.08 & 0.28 & 2.42 & 0.02 & 1.32 & 0.19 & 0.52 & 0.60 \\
\hline Culture5 & 0.43 & 0.67 & -0.65 & 0.52 & 0.92 & 0.36 & -0.24 & 0.81 & -0.67 & 0.50 \\
\hline \multicolumn{11}{|c|}{ Length of stay: 2 years to just under 4 years vs. 10 years or more } \\
\hline & $\mathrm{t}$ & alpha & $\mathrm{T}$ & alpha & $\mathrm{t}$ & alpha & $\mathrm{T}$ & alpha & $\mathrm{T}$ & alpha \\
\hline Culture1 & -1.78 & 0.08 & 0.75 & 0.46 & -1.02 & 0.31 & -.70 & 0.49 & -1.40 & 0.16 \\
\hline Culture2 & 0.33 & 0.18 & -0.47 & 0.64 & 1.79 & 0.07 & 1.73 & 0.08 & 0.27 & 0.79 \\
\hline Culture3 & 0.55 & 0.58 & 0.20 & 0.85 & 2.38 & 0.02 & 1.33 & 0.19 & 0.66 & 0.51 \\
\hline Culture4 & 0.51 & 0.61 & 0.26 & 0.79 & 2.05 & 0.04 & 1.85 & 0.07 & 0.34 & 0.73 \\
\hline Culture5 & 2.06 & 0.04 & -0.94 & 0.35 & 0.12 & 0.90 & 1.05 & 0.30 & -1.68 & 0.09 \\
\hline
\end{tabular}

Culture1: An increasing number of people of different cultures makes Indy a much better place to live;

Culture2: I enjoy the cultural attractions the city has to offer;

Culture3: I am aware of the city's recent accomplishments in cultural tourism;

Culture4: I am aware of the city's cultural district program (2004-2006) or I am aware of the city's plans for developing the cultural trail (2007-2008);

Culture5: Indy has the potential to succeed as a cultural tourism destination) 


\section{Table 6: Relationships between Overall QOL Satisfaction and Cultural Tourism} Attributes (Based on surveys of 2007 and 2008)

\begin{tabular}{|c|c|c|c|c|c|c|}
\hline \multicolumn{2}{|l|}{ 2007: } & Culture1 & Culture2 & Culture3 & Culture4 & Culture5 \\
\hline \multirow{3}{*}{$\begin{array}{l}\text { Overall QOL } \\
\text { Satisfaction } \\
\text { (mean: } 2.23 \text { ) }\end{array}$} & Pearson Correlation & $0.276^{\star \star}$ & $0.290^{* \star}$ & 0.099 & 0.067 & $0.182^{\text {t* }}$ \\
\hline & Sig. (2-tailed) & 0.000 & 0.000 & 0.136 & 0.314 & 0.006 \\
\hline & $\mathrm{N}$ & 226 & 228 & 229 & 229 & 229 \\
\hline \multicolumn{2}{|l|}{ 2008: } & Culture1 & Culture2 & Culture3 & Culture4 & Culture5 \\
\hline \multirow{3}{*}{$\begin{array}{l}\text { Overall QOL } \\
\text { Satisfaction } \\
\text { (mean: } 2.07 \text { ) }\end{array}$} & Pearson Correlation & 0.113 & $0.140^{*}$ & 0.106 & $0.180^{* \star}$ & $0.169^{\star \star}$ \\
\hline & Sig. (2-tailed) & 0.064 & 0.025 & 0.082 & 0.003 & 0.008 \\
\hline & $\mathrm{N}$ & 269 & 258 & 269 & 270 & 248 \\
\hline
\end{tabular}

*. Correlation is significant at the 0.05 level (2-tailed).

**. Correlation is significant at the 0.01 level (2-tailed).

Furthermore, no distinctive changes were observed of people's perceptions of QOL and cultural tourism development throughout the five-year survey and no strong relationships were found between residents' overall QOL satisfaction and their perceptions of the importance of cultural tourism development in this longitudinal study. One implication of is that the level of residents' awareness of the importance of cultural tourism may still be low and the city government and tourism marketers still need to work together to support this initiative through increased financial support and marketing activities. As previously mentioned, measurement of people' $\mathrm{QOL}$ is a complicated process which requires the inclusion of both objective and subjective criteria. One practical implication based on the findings is that the cultural tourism operators and administrators in Indianapolis should take a different marketing approach, particularly at this time of economic downturn, to promote residents' participation. As the city has gained support of cultural tourism from its residents, it will be much more cost-effective to promote the city's cultural tourism offerings locally and regionally by word-of-mouth, e-marketing or limited advertising.

QOL is a composite index of several life domains such as health, wealth, safety and community pride. The results show that the impact of cultural tourism is relatively limited as compared with other life domains. Residents at this stage may still be more concerned about their basic QOL elements such as wealth, health and safety issues. Results of the study further indicates that it may still be early to evaluate the impact and change of Indianapolis' attitudes about the city's cultural tourism development, as well as, its relationship with people's overall QOL. According to Kim (2002), people's life satisfaction is higher during the maturity tourism development stage; hence, repeating the study in future years may yield different findings.

In a recent article in the Inside Indiana Business (2009), it was noted that the declining economy has a direct negative impact on cultural tourism promotions around the state mainly through reduction in funding from traditional cultural tourism supporters, such as local governments and endowments. One bright note is the anticipated increase in in-state travel by cost-conscious Indiana residents. In conclusion, significant efforts, at all levels, still need to be considered by the city's leadership if Indianapolis is to be recognized as an international cultural tourism destination.

This is the first longitudinal study in the literature that measures the influence of cultural tourism on QOL, and there were also several 
limitations to the study. The study was conducted in a block of the city's downtown area. Residents who were surveyed may be limited to those who work in that area or those who visit the place for certain purposes. Because of this, the demographics of those participants may not represent the entire city population. The instruments were administered face-to-face at the same location with a short time period in September or October for all five years. Therefore, the two limitations of the study are the degree to which the investigators could capture the full range and scope of the population under investigation and the study's limited time frame.

In future studies, it is suggested to investigate people living in different locations of the city to make the results are more representative of the population. Different results may be reported if the residents are not working in the downtown area. Additional quantitative statistical methods and qualitative research techniques can be used to further validate the instrument and continue to examine the data yielding other significant findings to contribute to the body of knowledge.

\section{References}

Anderson, D \& Nurick, J. (2002). Cultural Impact: Measuring the economic effects of culture. Locum Destination Review, 10(1), 15-17.

Avgoustis, S. H., Cecil, A.K., Fu, Y., \& Wang, S. (2005). Exploring the relationship between cultural tourism and QOL. Annual Conference Proceedings of Research and Academic Papers, Volume XVII, 232-241. Chicago, Illinois.

Cabrini, L. (2003). Cultural tourism: opportunities and challenges. European Forum of World Heritage Cities. URL: http://www.heritageforum.org/

Cameron, C. (1993). Cultural tourism: Gold mine or lane mind? Communications Canada Conference.

Cecil, A., Wang, S., Fu, Y. \& Avgoustis, S.H. (2007). Exploring resident awareness of cultural tourism and its impact on
QOL. European Journal of Tourism Research, 1(1), pp. 38-52.

Cohen, E. (1978). Impact of tourism on the physical environment. Annals of Tourism Research, 5(2), pp. 215-237.

Diener, E., \& Shu, E. (1997). Measuring quality of life: Economic, Social, and Subjective Indicators. Social Indicators Research, 40(1-2), pp. 189-216.

Fu, Y, Cecil, A. K., Wang, S. and Avgoustis, S. H. (2007). Predicting residents' perceptions of cultural tourism attractiveness. Tourism Today 7, pp. 125-138.

Indianapolis Cultural Tourism Initiative (2005). www.culturalindy.org (Accessed on 20.05.2009)

Inside Indiana Business (2009). http://www.insideindianabusiness.com/ newsitem.asp?ID=35560\#middle (Accessed on 24.05.2009)

Jurowski, C., Uysal, M. \& Williams, D. (1997). A theoretical analysis of host community resident reactions to tourism. Journal of Travel Research, 36(2), pp. 3-11.

Kim, K. (2002). The effects of tourism impacts upon QOL of residents in the community. Unpublished doctoral dissertation, Virginia Polytechnic Institute and State University.

Linton, N. (1987). Trends in tourism and development - values, sustainability, and stewardship. Tourism Management, 12(2), pp. 122-118.

Law, C. M. (2002). Urban Tourism: The visitor economy and the growth of large cities. New York: Continuum.

Perdue, R., Long, P. \& Allen, L. (1990). Resident support for tourism development. Annals of Tourism Research, 17(4), pp. 586-599.

Raphael, D., Steinmetz, B. and Renwick, R. (1998). How to carry out a community QOL project: A manual, a health promotion approach to understanding communities. Toronto: University of Toronto.

Wang, S., Fu, Y., Cecil, A. K., \& Avgoustis, S. H. (2008). Impacts of cultural tourism upon quality of life: The residents' perspective. Proceedings of the 2008 
International CHRIE Conference, pp. 516-523.

Wang, S, Fu, Y., Cecil, A.K., \& Avgoustis, S. H. (2006). Residents' perceptions of cultural tourism and QOL: A longitudinal approach, Tourism Today, 5, pp. 47-61.

Williams, A.M. \& Shaw, G. (1988). Tourism and development, in tourism and economic development: Western European experiences. London: Belhaven Press.

Yamada, N., Heo, J., King, C., \& Fu, Y. (2009). Life Satisfaction of Urban Residents: Do Health Perception, Wealth, Cultural Tourism, Safety, and Community Pride Matter? Proceedings of 2009 International Council on Hotel, Restaurant and Institutional Education's Annual Convention. San Francisco, CA. 